\title{
Literary Scholars’ Disciplinary Literacy Orientations
}

\author{
ERIC D. RACKLEY \\ Brigham Young University - Hawaii
}

\begin{abstract}
This study examines how four university-based literary scholars in the United States read literary texts. Findings suggest that the scholars used four related literary literacy orientations in their reading: They attended to their affective experiences with literature, built recursive interpretations of literature, contextualized literature, and recognized and managed literary complexity. As broad-level disciplinary ways of navigating literature, these literary literacy orientations included the scholars' meaning-making practices as well as their beliefs, feelings, and attitudes about literature and making sense of it. Findings support and build upon existing scholarship on English disciplinary literacies and offer paths for further research.
\end{abstract}

\section{Introduction}

When asked about the role of literature in his field, literary scholar, Oscar said, "It's the core of what English does." Oscar's words capture the centrality of texts in academic domains, such as the English language arts, and the sense that readers should "do" something with them. But how do readers "do" literature? What do they "do" with it? And when should they "do" it? The production, interpretation, and use of literature plays an important role in English disciplinary literacy, in large part because it draws attention to "doing" literature in ways that align with disciplinary ways of working, thinking, and constructing meaning (Goldman et al., 2016). To date, much of the limited scholarship related to English disciplinary literacies has focused on identifying individual strategies literary scholars and other English experts use to make sense of texts (e.g. Peskin, 1998; Reynolds \& Rush, 2017). Although this work has made important contributions to the field, disciplinary privileged ways of knowing in English have received sparse attention in the empirical literature (Rainey \& Moje, 2012), leaving researchers, educators, and students with limited understanding of the range of disciplinary tools, practices, and experiences literary scholars use in their work with literary texts.

From a disciplinary literacy perspective, this study explores how literary scholars "do" literature by looking closely at the way four university-based literary researchers, theorists, and practitioners in the United States construct meaning of literary texts. The following questions operationalize this focus:

1. What disciplinary situated approaches do literary scholars use to read literature?

2. What disciplinary experiences shape these scholars' approaches to literature?

Although literacy strategies are an important part of developing expertise in English and other fields, strategies alone are not enough to do the work of the disciplines. Moje (2011) argued that "strategies - absent some level of knowledge, a purpose for engaging in the literate practice, and an identification with the domain or the purpose for reading will not take readers and writers very far" (p. 52). Learners need deep content knowledge 
and conceptual understanding of how disciplines work in order to use strategies effectively to construct disciplinary knowledge (Pearson, 2011). As a field, we must understand more about scholars' ways of knowing with literature, what Rush and Scherff (2013) referred to as "the mysteries of disciplinary discourse, practices, and knowledge" (p. 320). This requires a fuller conceptualization of literacy learning and instruction that lies at the intersection of knowledge, discourses, and identity and consists of social, cultural, and affective experiences that go beyond "the accumulation of skills" (Moje, 2015, p. 255).

Guided by the aforementioned research questions, this study explores issues related to English disciplinary literacy by attending to literary scholars' literacy orientations, or broad-level disciplinary ways of experiencing and navigating literature that consist of scholars' core beliefs, attitudes, feelings, and approaches to literary text. Richer and more inclusive than individual reading strategies that have been central to much of the extant English experts' literacy research, literary literacy orientations offer robust disciplinary ways of seeing, experiencing, and engaging with literature. Attention to literary scholars' literacy orientations can add important insights to our understanding of how the English discipline works and how literary scholars engage with and "do" literature.

\section{Theoretical Framework and Relevant Literature}

\section{Disciplinary Literacy}

Literacy is always domain specific insofar as it occurs in certain contexts, with certain texts, for certain purposes. Disciplinary literacy is also domain specific; however, it emphasizes the development of disciplinary knowledge in specific domains of study, such as mathematics, history, science, or English (Shanahan \& Shanahan, 2018). As part of socially constructed "conceptual contexts" (Grossman \& Stodolsky, 1995) or disciplinary (sub)cultures (Ball \& Lacey, 1984) that have distinctive linguistic representations (Fang, 2017) and their own norms of behavior, histories, epistemologies, and expectations for developing and using knowledge, disciplines are primarily defined by their differences. These differences help frame the work of the disciplines and create the specialized contexts that inform what counts as literacy (Shanahan \& Shanahan, 2012). Indeed, disciplines, as communities of discourse, are highly specialized human constructs that require learning specific practices, procedures, conventions, and rituals (Moje, 2015). Developing this specialized knowledge of how disciplines work helps position one, in socially recognizable ways, as an insider with the appropriate sets of tools and understandings valued in specific domains of study.

Importantly, because disciplinary literacy conceptualizes disciplines as contexts in which domain-specific knowledge is produced, it recognizes the strategic ways of generating this specialized knowledge (Shanahan \& Shanahan, 2008). This includes attention to the habits, practices, and ways of reading, writing, working, and thinking engaged in by those who generate and use disciplinary knowledge, a process Fang and Coatoam (2013) refer to as the development of "disciplinary habits of mind" (p. 628). Mathematicians, for example, privilege precision, economy of expression, and quantification more than other disciplines. As they work through the linguistic, symbolic, and visual systems common in mathematical texts (Schleppegrell, 2007), mathematicians tend to "read slowly, carefully, word-by-word (or figure) to understand the text fully and 
to reduce the likelihood of error" (Shanahan \& Shanahan, 2018, p. 297). For historians, texts are interpretations of history that reverberate with "a cacophony of voices" (Wineburg, 2005, p. 662). To navigate these voices, historians consider the time, place, and situation in which a document was produced (contextualization), issues of authorship such as who wrote the text and why (sourcing), and the nature of connections and (dis)agreements among related documents (corroboration) (Wineburg, 1991). For their part, literary scholars examine fictional representations of the world - literature, poetry, and drama, for example - through the analysis of figurative language, characterization, narrative development, and other literary elements (Goldman, et al., 2016). Their work involves "the ability to wrestle with complexities that characterize the conundrums of the human condition" (Lee, Goldman, Levin, \& Magliano, 2016, p. 168) and unlike other disciplines, in literary studies emotional investment and affective response are appropriate elements of interpretation (Levine, 2014; Thein, Guise, \& Sloan, 2015). Among these and other disciplines, the specialized approaches experts use to generate, communicate, and evaluate knowledge are informed by the distinct features, structures, and cultures of their respective domains of study.

\section{Empirical Studies of English Disciplinary Approaches to Literacy}

Notwithstanding the centrality of English language arts as a domain of study and schooling, there has been a limited amount of empirical research devoted to understanding English disciplinary approaches to literacy (Rainey \& Moje, 2012). Research designed to understand how literary experts engage with and attempt to understand literature is, however, growing. As derived from the existing literary expert performance study research, three related assumptions inform the present study: Literary scholars use domain-specific practices to understand literature, they approach literature more skillfully than literary novices, and less-well documented, but still apparent, literary experts have affective experiences with literary texts.

In an early literary performance study, Dorfman (1996) evaluated the interpretive strategies of graduate students in English and computer science majors. Participants read short stories with different levels of accessibility and complexity and then responded to them across four dimensions: comprehension, affect, interpretative, and literary/critical. Compared to novices, experts knew more about literary interpretive conventions, were able to assess a text's quality apart from their ability to understand it, and developed layers of literary understanding. Experts also enjoyed literary texts more, found them to be more interesting, and were more willing to draw inferences from texts that they may not have understood. In a related study, Peskin (1998) compared the approaches English doctoral students and undergraduates used to make sense of two difficult and unfamiliar poems. Peskin argued that the experts' comparatively rich reservoir of literary knowledge allowed them to make more allusions to other texts, quickly identify genre conventions and historical contexts, and anticipate what was coming in the poems. The literary experts also provided more in-depth explorations of the poems' significance, looked for meaning at the intersection of contradictions, and employed specific tools to interpret the poems, such as using language and poetic structures as interpretive cues. More so than the novices, the experts were satisfied with their literary experiences, conveying appreciation and enjoyment of the poems. 
The literary scholars in Rainey's (2017) study demonstrated a set of shared, disciplinary literacy practices, approaches to teaching, and orientations. The scholars constructed knowledge of literary texts by looking for patterns, identifying strangeness or confusion, and considering various contexts that informed a literary work, such as the time of its creation, the scholarship surrounding it, and relevant authorial information. These shared literacy practices rested upon two literary literacy orientations. The first dealt with the social nature of literary studies in that the scholars indicated they were part of a larger, academic or interpretive community that guided their work. The second orientation addressed the importance of constructing disciplinary knowledge by "pursing literary problems" (Rainey, 2017, p. 61). Aligned with previous English disciplinary literary research, Reynolds and Rush (2017) studied how English professors and college freshman read literature. They found key differences in the approaches used by both groups. Novices, for example, read for basic comprehension while experts appeared to build interpretations of the texts. More so than novices, literary experts hypothesized about the texts' language, character relationships, and tone. Experts and novices also both asked questions as they read, but the experts used their questions as jumping-off points for more in-depth literary interpretations, self-dialogue about the texts, and opening "new pathways of analysis" (Reynolds \& Rush, 2017, p. 210). Novices tended to ask questions without attempting to address them. Asking a question was the end of novices' literary meaning-making processes, not, as it was for the experts, the beginning.

As a means of identifying English experts' literary meaning-making practices, extant research has made important contributions to English disciplinary literacies. But gaps remain. The research, for example, addresses literary scholars' affective experiences with literature, but it does so rarely and in limited ways. Moje (2015) argued that literacy learning and instruction should include attention to "affect and emotion, imagination and curiosity, value and purpose" (p. 255). She also asked, "How do we support the development of disciplinary literacy practice as a human, social construction rather than merely the learning of discrete skills?" (p. 255). To date, the research on English scholars' literature-based literacies has privileged the identification of individual, literacy practices and/or measurements of literary domain knowledge and has seldom sought to empirically identify broad-level disciplinary conceptualizations, values, and experiences that organize and guide scholars' literary meaning-making work.

These gaps provide openings for improving our understanding of the role and nature of literary scholars' work with literature. The present study adds important disciplinary contours to the current body of research by looking beyond discrete skills to identify some of the literacy orientations that explain literary scholars' text-based, cognitive, and affective literary literacy experiences. Literary literacy orientations, by design, convey core beliefs and attitudes about and basic approaches for conceptualizing and engaging in the construction of literary meaning. Orientations are broader than and inclusive of individual literacy skills and practices and represent English-oriented ways of thinking about, experiencing, and engaging with literary texts. Identifying guiding English disciplinary literacy orientations adds another layer to this body of research by offering new ways of understanding literary scholars' meaning-making approaches to literature. 


\section{Research Design and Methodology}

\section{Participants}

Participants were selected for their disciplinary affiliations and levels of expertise. Two of the participants were English professors and two were English instructors. David, Louis, and Sophie had terminal degrees in English and Oscar had an M.A. in English (all names are pseudonyms). The participants received their highest degrees from Princeton University, University of Edinburg, and University of Hawaii-Manoa, all of which are research intensive institutions (Carnegie Classification of Institutions of Higher Education, 2018; Times Higher Education, 2019). The scholars had a range of specializations, years of experience in the field, and taught a variety of graduate and undergraduate courses. All participants were employed full-time in English departments at research institutions in the United States and were actively engaged in literature-based analysis, publication, and instruction. One participant was female. Three were male (Table 1).

The number and nature of experts involved in this study is consistent with some of the current research on disciplinary experts' literacy practices (McCarthy \& Goldman, 2019; Reynolds \& Rush, 2017; Shanahan, Shanahan, \& Misischia, 2011). The participants in this body of research are characterized by their advanced academic degrees and expertise in relevant fields of study. Given the academic credentials and literary experiences of the scholars in the present study, they represent a purposeful sample (Maxwell, 2013) of a diverse population of literary experts. Although the literary scholars in this study were drawn from a variety of specializations in English, there was coherence in their approaches to literature.

\section{Data Sources and Collection}

Mindful of the contributions interviewing research has made in understanding the nature of skillful performance in cognitive science (Newell \& Simon, 1972), reading comprehension (Pressley \& Afflerbach, 1995), and literary literacy research (Rainey, 2017), this study employs it to examine the ways in which literary scholars read literature. Consistent with Seidman's (2013) conceptualization of interviews as meaning-making processes, the two types of interviews for this study were designed to provide the participants with opportunities to (re)construct accounts of their experiences with literary texts (semi-structured interviews) and how they generated meaning from them (performance interviews).

Semi-Structured Interviews. Aimed at developing insights that were not directly observable, the semi-structured interviews were designed to explore scholars' views of and past experiences with English, literacy, motivation for literacy, and literacy teaching and learning. These interviews lasted 60-90 minutes. Of the six types of questions Patton (2015) suggested to stimulate participant responses, the semi-structured interviews included four: background, experience, opinion, and knowledge questions. Although feeling questions were not an intentional part of the protocol, participants readily shared their feelings about relevant experiences, which seemed to "tap the affective dimension" (Patton, 2015, p. 444) of the experts' interactions with literature. The semi-structured nature of these interviews allowed a focus on key issues related to the study and the flexibility to follow relevant 
threads of inquiry as they emerged. Because it was not possible to directly observe the literary experts' experiences with literature in the semi-structured interviews, performance interviews provided another lens for observing and understanding how they constructed meaning of literary texts.

Performance Interviews. To capture the scholars' complex, "constructively responsive" (Pressley \& Afflerbach, 1995, p. 2) literary meaning-making processes, the second interview primarily involved concurrent and retrospective verbal reading protocols (Hilden \& Pressley, 2011). Participants selected texts to read for the verbal protocols that they were familiar with or used in their instruction (Table 1). These interviews began with questions about the scholars' familiarity with the texts they selected and a brief explanation of the purpose of the interview, which was to understand how they read literature. The interviewer then asked the participants to read their texts aloud as they normally would, but pause to share their thinking as they read. The participants were told that everything they thought was important and that they should share their thoughts as they came to them (Ericsson \& Simon, 1993). As they read, the interviewer prompted the scholars with "Please keep talking," and "What are you thinking?" After reading their texts, the participants were invited to reflect on their experiences and the processes they used as they read. Including the pre- and post-verbal protocol questions, these interviews lasted 45-60 minutes.

Table 1

Profiles of Participants and Verbal Protocol Text Selections

\begin{tabular}{|c|c|c|c|c|c|}
\hline Pseudonym & Position & $\begin{array}{l}\text { Highest } \\
\text { degree }\end{array}$ & $\begin{array}{l}\text { Years of } \\
\text { experience }\end{array}$ & $\begin{array}{l}\text { Specializations and } \\
\text { academic interests }\end{array}$ & Text selection \\
\hline David & Professor & Ph.D. & 38 & $\begin{array}{l}\text { Biography and life } \\
\text { writing, literary } \\
\text { theory, drama and } \\
\text { performance, } \\
\text { research methods, } \\
\text { professional editing }\end{array}$ & $\begin{array}{l}\text { Play excerpt: } \\
\text { Tony Kushner } \\
\text { (2013). Angels } \\
\text { in America: A } \\
\text { Gay Fantasia } \\
\text { on National } \\
\text { Themes. }\end{array}$ \\
\hline Louis & Professor & Ph.D. & 22 & $\begin{array}{l}\text { 19th-century British } \\
\text { literature, 19th- } \\
\text { century popular } \\
\text { culture, Sir Walter } \\
\text { Scott, Robert Louis } \\
\text { Stevenson }\end{array}$ & $\begin{array}{l}\text { Fable: Robert } \\
\text { Louis Stevenson } \\
\text { (n.d.). 'The } \\
\text { Cart-Horses and } \\
\text { the Saddle- } \\
\text { Horse'. }\end{array}$ \\
\hline Sophie & Instructor & Ph.D. & 6 & $\begin{array}{l}\text { Poetry and national } \\
\text { identity, long-form } \\
\text { poems, science } \\
\text { fiction poetry, poetry } \\
\text { as technology, } \\
\text { composition, } \\
\text { pedagogy }\end{array}$ & $\begin{array}{l}\text { Novel excerpt: } \\
\text { Anne Carson } \\
\text { (2013). Red Doc } \\
\text { >. } \\
\text { Book excerpt: } \\
\text { Seamus Heaney } \\
\text { (1995). The }\end{array}$ \\
\hline
\end{tabular}




\begin{tabular}{|c|c|c|c|c|c|}
\hline & & & & & $\begin{array}{l}\text { Redress of } \\
\text { Poetry. }\end{array}$ \\
\hline Oscar & Instructor & M.A. & 6 & $\begin{array}{l}\text { Creative writing and } \\
\text { composition, Asian- } \\
\text { American literature, } \\
\text { Pacific literature, } \\
\text { representation and } \\
\text { identity }\end{array}$ & $\begin{array}{l}\text { Poem: Kalani } \\
\text { Akana (2014). } \\
\text { 'Da 23 } 3^{\text {rd }} \text { Psalm'. } \\
\text { Poem: } \\
\text { Emelihter } \\
\text { Kihleng (2008). } \\
\text { 'Lokaiahn Wai'. }\end{array}$ \\
\hline
\end{tabular}

Together, the pair of interviews provided insight into some of the literary experts' observable (performance interview) and unobservable (semi-structured interview) experiences with literature. They also allowed the participants to (re)construct accounts of their literary-based experiences with questions that tapped into their background, opinions, knowledge, experiences, and feelings as they related to literature and making sense of it. Formal analysis occurred after all the semi-structured and verbal protocol interviews were transcribed.

\section{Analytic Procedures}

Informed by methods of constant comparative analysis (Corbin \& Strauss, 2015), a colleague and I read and reread the semi-structured interviews, engaging in extended micro-analyses individually and then meeting to discuss our codes and our coding processes. We coded the data with tentative labels that focused on identifying how the scholars constructed meaning of literature. Early on we noticed that in addition to explaining their literary literacy practices, the scholars also shared their experiences, feelings, interests, and attitudes with and about literature that appeared to influence how they interacted with it and made sense of it. We developed a coding scheme that included "literary literacy practices" and a new category we labelled "literary literacy experiences" to more completely capture the scholars' responses. The first round of analysis yielded a wide variety of inductive and descriptive codes that came directly from the data and described the scholars' literary literacy practices and experiences.

We then arranged the codes by scholar and began looking within and across the responses for larger categories that helped explain the relationships among the practices and experiences. Specifically, we examined the similarities and differences among the codes, wrote relational statements and analytic memos, and tried to identify broader organizing principles for the codes. We recognized that the scholars' beliefs, attitudes, approaches, and experiences often coalesced around central and repeating ideas. In time, our processes produced four categories, or orientations, which suggested ways of engaging with literature that were broader and more abstract than the individually coded practices and experiences. Ninety-four percent of the initial codes were accounted for by the four orientations: attending to affect, building interpretations, contextualizing texts, and managing complexity. 
Table 2

Coding Scheme and Data Exemplars

\begin{tabular}{|c|c|c|}
\hline Orientation & Definition & Data Exemplar \\
\hline Attending to Affect & $\begin{array}{l}\text { Paying attention to } \\
\text { emotive, personal, or } \\
\text { aesthetic experiences } \\
\text { with literature. }\end{array}$ & $\begin{array}{l}\text { "I adore that in her work .... I love that } \\
\text { image .... . I have an aesthetic appreciation for } \\
\text { it" (Sophie). } \\
\text { "I love that no matter what I'm reading is } \\
\text { going to give me a different kind of } \\
\text { connection. So, I'm going to feel like I'm part } \\
\text { of that book" (Oscar). }\end{array}$ \\
\hline $\begin{array}{l}\text { Building } \\
\text { Interpretations }\end{array}$ & $\begin{array}{l}\text { Developing informed } \\
\text { explanations of } \\
\text { language, structure, } \\
\text { and ideas through } \\
\text { recursive } \\
\text { interpretations of } \\
\text { literature. }\end{array}$ & $\begin{array}{l}\text { "The old dissecting room strategy where you } \\
\text { take something, put it on the table, and } \\
\text { everybody looks at it. You take it apart and } \\
\text { they can see that it does have parts" (David). } \\
\text { "It's very important to discuss what the } \\
\text { writing is as much as what the writing is } \\
\text { doing" (Oscar). }\end{array}$ \\
\hline $\begin{array}{l}\text { Contextualizing } \\
\text { Texts }\end{array}$ & $\begin{array}{l}\text { Situating literature } \\
\text { within relevant } \\
\text { historical, social, or } \\
\text { theoretical contexts. }\end{array}$ & $\begin{array}{l}\text { "It's very important to have a historical sense" } \\
\text { (David). } \\
\text { "[I read for] details of time, place, and } \\
\text { context. So, I'm reading The Master of } \\
\text { Ballantrae for about the fifth time right now. } \\
\text { So, time, place, and context, but [I'm looking } \\
\text { for the] nuance as well of all those things, } \\
\text { amongst other kinds of historical research that } \\
\text { I can bring to the narrative" (Louis). }\end{array}$ \\
\hline $\begin{array}{l}\text { Managing } \\
\text { Complexity }\end{array}$ & $\begin{array}{l}\text { Recognizing and } \\
\text { managing the various } \\
\text { complexities of } \\
\text { literature. }\end{array}$ & $\begin{array}{l}\text { "There's difficulty in general with the } \\
\text { expectation that they are trying to solve the } \\
\text { problem, which is reading the text" (Sophie). } \\
\text { "I don't know how familiar you are with } \\
\text { Richard III, but it's so complex" (Louis). }\end{array}$ \\
\hline
\end{tabular}

We then analyzed the verbal protocol interviews for supporting and contesting evidence of the orientations and additional literacy practices and experiences. Analyses of the verbal protocol interviews provided additional codes that fit into the existing orientations and many more instances of the practices and experiences identified previously. The four orientations mapped very closely on to the verbal protocol interview data, suggesting a high degree of alignment between the literary scholars' stated (unobservable) and enacted (observable) literacy practices and experiences with literature. Continuing to think through the data, we made theoretical comparisons between the developing orientations and extant scholarship on disciplinary literacy (Moje, 2007, 2015; Shanahan \& Shanahan, 2008, 2012) literary literacy (Rainey, 2017; Reynolds \& Rush, 2017), and literary theory (Iser, 1978; Rosenblatt, 1978). As we made our final passes through the data, we felt confident that the four disciplinary literacy orientations not only represented some of the literary scholars' core beliefs about and approaches to constructing 
meaning of literature, but were aligned with current literacy and literary research and practice.

\section{Literary Literacy Orientations}

Analyses indicate that all of the scholars identified four shared literary literacy orientations that guided their literary reading: attending to affect, building interpretations, contextualizing texts, and managing complexity. Although presented separately for clarity, the scholars discussed and used these orientations flexibly and in combination with each other to engage with and construct meaning of literature. The internal composition of the orientations varied. Some were heavy on literary practices, others on personal experiences with literature, and others were more distributed. The examination of each orientation includes a detailed description of the orientation, several in-depth examples to demonstrate what it looked like in practice, and a brief summary of the orientation.

\section{Attending to Affect}

Signaling the affective nature of their interactions with literary texts, scholars attended to emotional, aesthetic, and personal experiences with literature. The valence of these affective experiences was overwhelmingly positive. The scholars explained how much fun they had reading literature, the beauty of what they were reading, and the enthusiasm they had for it. The scholars also discussed their individual relationships with literature and explained how literature influenced them as readers and people. For them, constructing meaning of literature included a personal dimension that made reading a decidedly human and satisfying experience that Oscar hoped would lead young readers, over time, to discover that they "love the discipline." Speaking about readers' experiences with literary texts, Sophie said "because they mean something to me, I'd probably want them to mean something to you."

Louis talked about the personal bond he had with literature, explaining that he had "a relationship with the authors. I mean, truly. I know Stevenson, Walter Scott, and Joseph Conrad." Speaking of Conrad's (1990) Heart of Darkness, Louis said, "I'm pretty intimately related to that text; so immersed in that text." Throughout his first interview, he used "intimate" to describe his relationship with Dr. Jekyll and Mr. Hyde (Stevenson, 2002), Frankenstein (Shelley, 1994), Hamlet (Shakespeare, 2012), and other literary works. "Let's be honest," Louis said. "They become your friends." To demonstrate the close relationship he developed with literary texts, Louis shared the following experience:

And I don't know how personal you want this to get, but I've been dealing with a lot of health issues, specifically cancer. I'm okay. That's what these scars are from. And honestly, reading these texts, like Hamlet, got me through more things than I care to relate because it just constantly touches on the themes that you're dealing with in real time. ... So, it does become very intimate.

Louis and the other scholars talked about authors and literary works as one might speak about a close friend. Hamlet, for example, helped Louis manage an illness by addressing issues he was dealing with in the moment. Much like a friendship, reader and text grew closer as they spent time together, in this case, during a difficult experience. And like a friendship, there appeared to be layers to what scholar and text could share, and had shared. 
Speaking about Seamus Heaney, Sophie said "There have been times in my academic life where it felt like I really needed his guidance." Oscar explained his relationship with literature and literary authors by saying he "felt a lot of kinship" with them and that he had "a deep connection to the literature." As demonstrated by the scholars' experiences, the relationships they had with authors and literary texts were beautiful, poignant, and "hugely important to us [and] our understanding of ourselves." David offered the following example of his developing relationship with literature:

I suddenly started realizing in these [Victorian novels] that I've been reading for 20 years that the middle-aged characters were actually interesting. I've been finding the elderly characters - I didn't even notice they were there before, but actually they're really interesting. The books and literature and stories are companions to your life and they are a kind of gauge as to your own development and what's important along the way. Books actually provide templates for understanding the world.

As a guide for his personal development, literature helped David navigate and rethink his experiences. Literature, it seemed, provided a way for David to understand the world and that stories could be companions for him. To some degree, literary texts were tools for living. Moving beyond a strictly academic relationship, literature appeared to provide the scholars with ways for thinking about their lives and how they could live in a complex world. The scholars' affective orientation toward literature suggests that emotional and personal experiences and relationships with literary texts provided a lens for understanding them. That is, how the scholars felt about literature and the nature of their relationship with it was a way of coming into contact with literature and generating literary knowledge. At some level, reading literature was about understanding the problems of the human experience, in part, through their own experiences with it.

\section{Building Interpretations}

The scholars also developed explanations of literary language, structure, and ideas through recursive interpretations. For the scholars, literature never meant only one thing. There was always more to discover. The scholars' work involved generating additional possible readings of literary texts based on their experiences, purposes, knowledge, interests, and language and text structures. For them, interpretations offered depth, perspective, and understanding.

As she read Anne Carson's (2013) Red Doc >, Sophie focused on examining "ionizes" in the line "She ionizes the room as a Taoist rainmaker raises his voice to the clouds at the very moment the dragons come charging out" (p. 110). "I love the phrasing," Sophie said. Then, looking more closely at the use of language, she explained, "I think she's trying to communicate this sense of energy, like when somebody does something and it's either really thrilling or it's really risky and happening in front of an audience." Here, Sophie offered insight into Carson's use of "ionizes" by suggesting a way to interpret the word as it was embedded in a phrase, as part of a larger text. Sophie developed her insight through an example that demonstrated the type of energy she imagined the word invoking: A public display of "thrilling" or "risky" behavior. Sophie continued building her interpretation by considering the internal state of those who "ionize a room": 
You're not supposed to - you're not sure if everybody's okay with it. And if they're not okay with it, is that because they're embarrassed or because they're uncomfortable? Like, how much is it because of their own insecurities versus how much of it is because [social conventions] have been transgressed in some way?

As she developed her interpretation, Sophie drew on an understanding of human nature, wondering aloud why energizing a room with one's actions would be socially dicey. Is it because "you're not supposed to" do it, or because you are embarrassed? And does this stem from personal insecurities or from a realization that one is violating social conventions? In her examination of Carson's use of language, Sophie moved toward a social psychology of action, providing another way of understanding literature that was grounded in the text and her reading of it. She called this process "intellectual work" and "textual work" of the kind that builds disciplinary "willpower . . . and a cognitive capacity for inference."

Asking questions also helped the scholars build interpretations. All the scholars asked questions during their verbal protocol interviews and discussed the role of questions in their literary instruction. Oscar, for example, used a three-question approach for developing literary knowledge. He started with "What does it mean?" and followed up with "how" or "why." This approach might be seen to extend Sophie's interpretation of Carson's use of "ionizes" insofar as Sophie's interpretation sought meaning. Oscar's three-question approach asked a question that took possible meanings as a starting place and then examined the evidence for those interpretations - how one might have reached them or why one might think the way they do. There were no easy answers to the scholars' questions. Indeed, part of the value of their questions was giving them opportunities to wrestle with literary uncertainties, or as Sophie stated, developing the capacity "to be comfortable with ambiguity," which kept interpretive possibilities alive.

Asking questions to build interpretations extended literary inquiry, or as Oscar argued, promoted depth of understanding by inciting disciplinary thinking or "a disciplinary mindset" (Spires, Kerkhoff, \& Paul, 2020, p. 10). Recursive questioning also conveyed the disciplinary reality that "there's always more. There's always a question after a question" that can help readers excavate literary texts. Each line, as Sophie explained, was potentially "so rich that it wouldn't be possible to get everything [out of it]." Asking questions as a way of building interpretations could encourage readers "to think "Why would this be cool?"' and begin to realize that a text, a line, or a word may mean more than one initially thought. Asking questions of literature may be one representation of the scholars' disciplinary curiosity. They appeared to relish the work of building interpretations and developing new ways of understanding texts, authors, language, and ideas. Oscar called literature and attempts to understand it "the core of what English does." David argued that narrative is "absolutely fundamental to the way that we understand the world." In some ways, interpretation was the lifeblood of meaning-making for the scholars as they sought to understand literature in ways that problematized assumptions about language and form and extended their understanding of the human experience.

\section{Contextualizing Literature}

As part of their disciplinary meaning-making work, all of the scholars situated literature within historical, social, cultural, and theoretical contexts in an effort to 
understand it. Louis contextualized his reading by drawing attention to "details of time, place, and context." This included being familiar with an author's history with a text, understanding some of the culturally situated knowledge that informed the creation of a text, and knowing the people and texts that influenced their understanding of a literary idea and the development of a literary work. The guiding assumption for the scholars appeared to be that literature was a product of its environment and, therefore, being familiar with the influences that gave it life could help one make sense of it.

For example, scholars indicated that developing culturally situated knowledge helped generate literary meaning. In the following excerpt, David explained some of the knowledge and ideas one would need to understand to make sense of Hawaiian literature: "You actually have to be able to distinguish between crustaceans. You need to know certain winds. You need to know certain plants because the metaphors that are being used assume that you will know those things." David referred to the development of this knowledge as "build[ing] up a kind of geographic and biological and botanical library" of the local, cultural context that one may need to draw from when reading Hawaiian literature. He conceptualized the development of contextual literary knowledge in terms of how you, as a reader, "situate yourself in relation to the material."

Relatedly, Oscar selected a Hawaiian representation of Psalm 23 entitled $\mathrm{Da} 23^{\text {rd }}$ Psalm (Akana, 2004) to read for his verbal protocol interview. The text was written in pidgin, used Hawaiian words, and referenced local objects, institutions, and ways of living. Oscar worried that a decontextualized reading of $\mathrm{Da} 23^{\text {rd }}$ Psalm would disadvantage readers and lead them to misinterpret the text and think it was trying to be disrespectful. The concreteness of $\mathrm{Da} 23^{\text {rd }}$ Psalm may strike some, as Oscar feared, as overly casual, pedestrian, or even disrespectful. "He go give me gel for my hair-make me look sharp/ Hook me up lai dat," for example, may be difficult for some to reconcile literarily with "Thou anointest my head with oil." Oscar argued that situating the text culturally could provide a richer reading experience, allowing one to appreciate $\mathrm{Da} 23^{\text {rd }} \mathrm{Psalm}$ 's culturally situated approach to a traditional literary work.

In his interview, Oscar provided some useful cultural context, explaining that the Halawa Valley Maximum Security Prison referenced in Da $23^{\text {rd }}$ Psalm was a local, material manifestation of despair representative of "the valley of the shadow of death." Oscar also explained that "brah," pidgin for "brother" and an abbreviation of "bruddah," was often used with close associates and suggested a sort of intimacy and trust between the speaker and the reader. "Brah" can also be used as emphasis. Understanding some of the cultural references and uses of language underscores the determination - and faith - demonstrated by the speaker: "Cuz he no like me fall/ Even tho I stay in Halawa valley maximum security/ Brah/ I no scared/ Cuz he stay watch my back."

The scholars' approach to contextualizing was also demonstrated in their use of key texts, authors, characters, and genres to understand literary concepts and literary works. Oscar explained Ursula LeGuin's $(1968,1970,1972)$ attention to language and power in The Earthsea Trilogy. "If you can know the true name of things," Oscar said, "then you have power over that thing." This, he argued, was demonstrated theoretically by Foucault. In an effort to clarify the structure of a poetic novel she was reading by David Rakoff (2013), Sophie explained Rakoff's use of tetrameter by comparing it to Shakespeare's use of pentameter. She compared the consistency of Rakoff's form to an epic poem and gave 
two examples, The Iliad (Homer, 1990) and The Odyssey (Homer, 1996). Using literature as examples, reference points, and a kind of short-hand helped the scholars understand other literary texts. Literature, in this case, was situated within literature. Literature was a context for understanding literature, suggesting that literary texts are not read in a vacuum and that one might use literary knowledge of one thing to generate meaning of another. Here, contextualizing literature appeared to sensitize the scholars to the broader environments surrounding literary works by providing additional material, lenses, and knowledge to aid in the explication of those works. For the scholars, understanding literature was informed in part by an understanding of the histories, cultures, and experiences that influenced its production.

\section{Managing Complexity}

The scholars also indicated that literary literacy involved recognizing and managing literature's complexities. They described making sense of literature as various forms of work and characterized the nature of the work as "really difficult," "complicated," and "problematic." Although navigating literature was difficult, it was not the "dreary surrender to convention" (McGraw \& Mason, 2019, p. 5) that some readers experience. The scholars welcomed the challenge. They seemed enlivened by it. David believed that challenge and complexity were baked into the discipline. "A fundamental tenant of English," he argued, "[is] that complication is really important." All the scholars recognized the place of complication in their disciplinary meaning-making insofar as literature was composed of "problem[s] to be solved."

Given the complex nature of literature and the difficulty of making sense of it, the scholars developed approaches to manage these complications. Louis used limited-focus reading. Because Richard III (Shakespeare, 2018) was difficult for students to understand Louis drew students' attention to specific elements of the text, and away from others. He told students:

We're going to start with the hardest thing you'll ever probably read in your life. You're going to spend three weeks doing it, but all I want you to focus on is Richard's character, the way the character either developed or is portrayed. I will explain the plot, so don't worry about that.

Drawing students' attention to Richard's character development was an attempt to help students manage the play's complexity. Given the play's challenges for readers, Louis wanted to "make sure not to freak them out," so he condensed their interaction with it into something he believed was less cumbersome, yet serviceable for constructing meaning. Recognizing that limiting students' attention to specific elements of the play would also limit their understanding of other elements of the play, Louis took it upon himself to fill in some of the gaps that were likely to occur, such as plot.

Another approach the scholars used to manage the complexity of literary literacy was approaching literature as a puzzle. Similar to limited-focus reading, a puzzling approach to literature sought to narrow the scholars' attention to specific areas they could investigate without taking on the entire work. Sophie described poetry as "very puzzlelike," and explained approaching it like she might approach a problem, asking, "How do I figure out what this means? What do I need to do? What would be a way [to] approach that text to figure out what [the author] is doing?" In her reading, Sophie demonstrated how 
she "figured out" problems in literature by narrowing her attention to specific areas that she sought to understand more clearly. Noticing, for example, issues related to Rakoff's (2013) poetic form, Sophie began looking for puzzles that, in this instance, focused on replicating his form: "[How do I] figure out how he made it? How would I start writing in this way? How would I reproduce this form?" As she continued reading, related puzzles emerged. Sophie considered how Rakoff made his narrative decisions, how he built fluidity among his ideas, and how he managed character actions. Clearly unable to address every aspect of the text, Sophie narrowed her literacy work to select problems that helped her manage the complexity of the literary meaning-making process.

Oscar approached literary challenges by identifying the nature of the struggle: "So, figure out what the struggle is," Oscar said. "Is it a language issue? . . . Is it a structure issue? ... Is it that I don't have enough context to understand this?" In Oscar's experience, uses of language, organization of texts, and situating texts in appropriate contexts could be particularly problematic when reading literature. Identifying the type of struggle could help manage these challenges by directing readers toward resources and tools for working through them. These meaning-making tools, Louis explained, allowed readers of literature to "appreciate a finite amount of material in more depth." Shaped in part by the place of complication in their field, Louis, Oscar, and the other scholars sought to manage the complexity of the literary meaning-making process, which was seen as a difficult, yet essential and rewarding task in their disciplinary literacy work.

\section{Discussion and Implications}

Consistent with theory and research on the disciplinary literacies of various academic domains, this study empirically identifies some of the ways literary disciplinarians conceptualized and engaged in their literacy work. Specifically, this study addressed two questions: What disciplinary situated approaches do literary scholars use to read literature? What disciplinary experiences shape the scholars' approaches to literature? Findings suggest that to construct meaning of literary texts, the scholars attended to their affective experiences with literature, built recursive interpretations of literary texts, contextualized literature, and recognized and managed literary complexity. These approaches represent core beliefs, attitudes, practices, and assumptions about what literary scholars "do" with literature and consist of individual literacy practices and experiences that demonstrate the scholars' literary literacy orientations, or broad disciplinary ways of conceptualizing and approaching literary-based meaning-making. These findings support and build upon existing scholarship on English disciplinary literacies and offer paths for further research.

Rainey (2017) identified two literary orientations - the social nature of literary studies and the pursuit of literary problems - that were foundational to the literary practices and instructional approaches used by the scholars in her study. Explicitly identifying broadlevel conceptualizations that informed literary scholars' meaning-making approaches with literature, these orientations are a jumping-off point for additional research. The present study extends Rainey's work by identifying and naming additional literary literacy orientations that English scholars used to inform their work with literature. These orientations are, by design, multivariate. Managing literary complexity, for example, highlights the complex nature of literature, the privileged status of complication, nuance, 
and conflict in English, and the several ways the scholars attempted to address them. Managing literary complexity, like the other orientations, is a broad-level literary literacy construct consisting of many domain-specific ways of experiencing and navigating literature that offers insight into literary scholars' work with texts. Meaning-making constructs at the orientation level may offer a profitable way of conceptualizing the literacy practices identified in English disciplinary literacies research as part of larger, more complex and domain-specific approaches to texts. Future work could investigate this new and developing literary literacy orientations space.

The literary literacy orientations in this study consisted of numerous practices, experiences, beliefs, and attitudes. Although these organizations seemed reasonable and in-line with existing literary and literacy theory and research (Peskin, 1998; Reynolds \& Rush, 2017; Iser, 1978; Rosenblatt, 1978), I recognize the flexibility of the orientations' make up. In this and other English-expert studies, for example, questioning serves an interpretive function (Rainey, 2017; Reynolds \& Rush, 2017); yet, questioning occupies a larger, disciplinary meaning-making space within the English domain that goes beyond interpretation. Depending upon the nature of one's questions, they might also be tools for contextualizing an indigenous poem, managing the complexity of a particularly dense literary passage, or solving issues of characterization or narrative conflict. In a word, questioning can serve many purposes and may be situated in ways that provide different disciplinary contours for constructing meaning and orienting readers' minds and experiences in relation to literature. The same may be said of other practices, experiences, and orientations within this study. Future research should be sensitive to the organization of disciplinary literacy practices and the way literary attitudes, experiences, discourses, and beliefs hang together to inform scholars' literary meaning-making work. What is the nature of these relationships? What are the situations in which their organizations shift? What theories might explain these shifting literary literacy relationships? Attention to these issues could improve our understanding of the composition and use of literary scholars' approaches to texts.

To date, a limited amount of English disciplinary literacies research has attended to literary scholars' affective and personal experiences with literature. Peskin (1998) and Dorfman (1996) found that literary experts appreciated their experiences with literature and enjoyed the work and processes of constructing meaning. The novices in both studies, by comparison, were less satisfied with literary texts, in part because they struggled to understand them. Recent research suggests that emotion is a key part of the English language arts context and plays a central role in students' literary learning and interpretation (Thein, Guise, \& Sloan, 2015). Levine (2014) and others (Levine \& Horton, 2013) have also argued that affect-laden evaluation is a useful heuristic for teaching students to interpret narrative texts. Yet, on the whole, literary experts' personal, affective experiences with literature has received scant attention and with rare exception is not studied as part of their meaning-making practice. This study identifies scholars' emotional and otherwise personal experiences with literature and conceptualizes it as an important aspect of their disciplinary work, not as an appendage to it. In this study, personal enjoyment of literature thread its way through much of the data. This is consistent with Thein et al. (2015) who argued that "emotion is always already in the fabric" of English language arts (p. 202). Future work in this area could investigate the nature of literary 
scholars' personal and affective experiences with literature and how these experiences inform their meaning-making practices. Future research, for example, might consider how affect and emotion - both positive and negative valences - work with skills and practices in the English language arts. What does this affect-intellect relationship look like across texts, genres, and authors in English-related contexts and with specific instructional activities?

In a study of the different reading practices among chemistry, mathematics, and history experts, Shanahan, Shanahan, and Misischia (2011) found that all the participants used similar strategies, but in different ways, for different purposes. Applicable to a different degree, the authors' observation could inform future work related to this study. This study makes no distinctions among the participants' various disciplinary specializations, treating them as essentially the same area of study. With a finer-grained approach that sought to identify the different literacy orientations according to the participants' specializations within the larger field of English, the shape of the findings may have been different. That is, attention to the subtleties of literary practice and experience among the various English disciplines could have provided new ways of understanding their approaches to texts. How did David's expertise in biography and Sophie's expertise in poetry, for example, influence their respective aesthetic responses to literature, if at all? Future research could look more thoroughly at the meaning-making approaches, experiences, and attitudes of the disciplinary subcultures (Ball \& Lacey, 1984) that clearly exist among the range of English disciplines. How do literary scholars' various specializations inform their approaches to texts? How do poets engage with literary texts in ways similar or different than literary theorists? Do literary critics approach narrative texts like dramatists? Do compositionalists experience the creation of texts differently than novelists? Are there places of overlap? These and other questions suggest a range of intricacies ripe for further examination within the various Englishes that are or can be represented in English disciplinary literacies.

The present examination of experts' literary literacy orientations also raises issues related to the professional foundation of prospective English language arts educators. Given the traditional attention to the study of literature in English language arts (Hillocks, 2016) and secondary and postsecondary students' widespread struggles with literature and literature-based courses (ACT, 2018; Xu, 2016) it is a mistake to assume that literary novices will develop a robust understanding of the discipline without clearly understanding disciplinary approaches of engaging with literature. A useful professional foundation for prospective ELA educators should include understanding literary experts' specialized meaning-making processes, including, for example, the orientations identified in this study. Knowing that these approaches exist is, of course, not enough. Nor is simply hoping students will intuit what are often latent disciplinary literary processes and use them appropriately with disciplinary texts. A more suitable pedagogy would be to teach novices disciplinary specialized approaches to interrogate literary texts through explicit, targeted instruction. Such instruction could include identifying specific approaches to literature and explaining their place, purpose, and value, demonstrating the approaches using relevant literary texts, providing frequent opportunities for novices to practice using the approaches with instructor support and feedback, and on-going evaluation of novices' use of the approaches and conversation about how they inform their construction of meaning of 
literature. Targeted, scaffolded instruction not only helps readers learn when, why, and how to use literary literacies to construct meaning, it may also aid in ameliorating "the hesitation - if not outright refusal" of some readers, including literary experts, to engage with unfamiliar literary texts (Warren, 2011, p. 369). Using appropriate instructional approaches to help literary novices learn to navigate the often complex "territory of literature" (Hillocks, 2016, p.109) in ways that align with the processes used by literary experts is an important part of a robust professional foundation for prospective ELA educators.

\section{Conclusion}

Notwithstanding the importance of disciplinary literacy in developing a clearer understanding of how disciplines work and identifying the specialized meaning-making practices of disciplinary experts (Shanahan \& Shanahan, 2018), research examining English-orientated approaches to literacy is scant. Much of the extant work has focused on measuring English scholars' domain knowledge and identifying their individual literacy practices. Moje (2015) has suggested a more comprehensive approach. Rather than focusing on "discrete literacy skills," Moje argues that disciplinary literacy should be more of "a human, social construction" (p. 255) that accounts for a range of experiences, values, and attitudes. For its part, the present study responds to this call and extends current disciplinary literacy research by moving beyond a focus on individual literacy skills to look more carefully at a fuller range of the text-based, social, and affective influences on literary scholars' approaches to literature. Specifically, this study empirically identifies and explores the nature of broad-level orientations that guide and inform the meaning-making work of literary scholars.

Moving forward, to improve the development of disciplinary literacy theory and practice, literacy researchers and educators must know more about the literacy processes that guide disciplinary experts. As a field, when we have a clearer view of how English experts conceptualize, organize, and engage in their meaning-making work we can make more informed decisions about how to prepare secondary teacher candidates and practicing teachers to develop (and problematize) the privileged frames of mind, discourses, and specialized approaches to literature. Moreover, with this clearer understanding, we will be better positioned to help learners understand how reading happens - or can happen - in literature-based classrooms in ways that align with disciplinary ways of "doing" literature.

\section{Ethics}

The research for this article was approved by the Institutional Review Board of Brigham Young University-Hawaii and was conducted in compliance with ethical and legal guidelines for social science research with human participants.

\section{References}

ACT. (2018). The condition of college and career readiness: National 2018. www.act.org/condition 2018

Ball, S., \& Lacey, C. (1984). Subject disciplines as the opportunity for a group action: A 
measured critique of subject as sub-culture. In A. Hargreaves \& P. Woods (Eds.), Classrooms and staffrooms: The sociology of teachers and teaching (pp. 234244). Open University Press.

Carnegie Classification of Institutions of Higher Education. (2018). Basic classification description. https://carnegieclassifications.iu.edu/classification_descriptions/basic.php

Corbin, J., \& Strauss, A. (2015). Basics of qualitative research (4th ed.). Sage.

Dorfman, M. H. (1996). Evaluating the interpretive community: Evidence from expert and novice readers. Poetics, 23(6), 453-470. https://doi.org/10.1016/0304$\underline{422 X(96) 00004-6}$

Ericsson, K. A., \& Simon, H. A. (1993). Protocol analysis: Verbal reports as data. MIT Press.

Fang, Z. (2017). Academic language and subject-area learning. In K. A. Hinchman and D. A. Apple (Eds.), Adolescent literacies: A handbook of practice-based research (pp.323-340). Guilford Press.

Fang, Z., \& Coatoam, S. (2013). Disciplinary literacy: What you want to know about it. Journal of Adolescent \& Adult Literacy, 56(8), 627-632.

Goldman, S. R., Britt, M. A., Brown, W., Cribb, G., George, M., Greenleaf, C., Lee, C. D., Shanahan, C., Project READI. (2016). Disciplinary literacies and learning to read for understanding: A conceptual framework for disciplinary literacy.

Educational Psychologist, 51(2), 219-246. https://doi.org/10.1080/00461520.2016.1168741

Grossman, P., \& Stodolsky, S. S. (1995). Content as context: The role of school subjects in secondary school teaching. Educational Researcher, 24(8), 5-11.

Hilden, K., \& Pressley, M. (2011). Verbal protocols of reading. In N. K. Duke and M. H. Mallette (Eds.), Literacy research methodologies (pp. 427-440). Guilford Press.

Hillocks, G. Jr., \& Smagorinsky, P. (Ed.) (2016). The territory of literature. English Education, 48(2), 109-126.

Iser, W. (1978). The act of reading: A theory of aesthetic response. Johns Hopkins University.

Lee, C. D. (2004). Literacy in the academic disciplines and the needs of adolescent struggling readers. Voices in Urban Education, 3, 14-25.

Lee, C. D., Goldman, S. R., Levin, S., \& Magliano, J. (2016). Epistemic cognition in literary reasoning. In J. A. Greene, W. A. Sandoval, \& I. Bråten (Eds.), Handbook of epistemic cognition (pp.165-183). Routledge.

Levine, S. (2014). Making interpretation visible with an affect-based strategy. Reading Research Quarterly, 49(3), 283-303.

Levine, S., \& Horton, W. S. (2013). Using affective appraisal to help readers construct literary interpretations. Scientific Study of Literature, 3(1), 105-136.

Maxwell, J.A. (2013). Qualitative research design: An interactive approach. Sage.

McCarthy, K. S., \& Goldman, S. R. (2019). Constructing interpretive inferences about literary texts: The role of domain-specific knowledge. Learning and Instruction, 60, 245-251. https://doi.org/10.1016/j.learninstruc.2017.12.004

McGraw, A., \& Mason, M. (2019). Reading in English classrooms: A developing culture 
of disenchantment. Changing English, 26(2), 137-149.

https://doi.org/10.1080/1358684X.2019.1585755

Merriam, S. B., \& Tisdell, E. J. (2016). Qualitative research: A guide to design and implementation. Jossey-Bass.

Moje, E. B. (2007). Developing socially just subject-matter instruction: A review of the literature on disciplinary literacy teaching. Review of Research in Education, 31(1), 1-44. https://doi.org/10.3102/0091732X07300046001

Moje, E. B. (2011). Developing disciplinary discourses and identities: What's knowledge got to do with it? In G. L. Bonilla \& K. Englander (Eds.), Discourses and identities in contexts of educational change (pp. 49-74). Peter Lang.

Moje, E. B. (2015). Doing and teaching disciplinary literacy with adolescent learners. A social and cultural enterprise. Harvard Educational Review, 85(2), 254-301.

Newell, A., \& Simon, H. A. (1972). Human problem solving. Prentice Hall.

Patton, M.Q. (2015). Qualitative research \& evaluation methods (4th ed.). Sage.

Pearson, P.D. (2011). Toward the next generation of comprehension instruction: A coda. In H. Daniels (Ed.), Comprehension going forward: Where we are/what's next (pp. 243-254). Heinemann.

Peskin, J. (1998). Constructing meaning when reading poetry: An expert-novice study. Cognition and Instruction, 16(3), 235-263.

Pressley, M., \& Afflerbach, P. (1995). Verbal protocols of reading: The nature of constructively responsive reading. Lawrence Erlbaum.

Rainey, E. C. (2017). Disciplinary literacy in English Language Arts: Exploring the social and problem-based nature of literary reading and reasoning. Reading Research Quarterly, 52(1), 53-71.

Rainey, E., \& Moje, E. B. (2012). Building insider knowledge: Teaching students to read, write, and think within ELA and across the disciplines. English Education, 45(1), 71-90.

Reynolds, T., \& Rush, L. S. (2017). Experts and novices reading literature: An analysis of disciplinary literacy in English Language Arts. Literacy Research and Instruction, 56(3), 199-216.

Rosenblatt, L. (1978). The reader, the text, the poem: The transactional theory of the literary work. Southern Illinois Press.

Rush, L. S., \& Scherff, L. (2013). Connecting across classrooms, communities, and disciplines. English Education, 45(4), 315-321.

Schleppegrell, M. J. (2007). The linguistic challenges of mathematics teaching and learning: A research review. Reading and Writing Quarterly, 23(2), 139-159. https://doi.org/10.1080/10573560601158461

Seidman, I. (2013). Interviewing as qualitative research: A guide for researchers in education and the social sciences (4th ed.). Teachers College Press.

Shanahan, C., \& Shanahan, T. (2018). Disciplinary literacy. In D. Lapp \& D. Fisher (Eds.), Handbook of research on teaching the English language arts (pp.281308). Routledge.

Shanahan, T., \& Shanahan, C. (2008). Teaching disciplinary literacy to adolescents: Rethinking content-area literacy. Harvard Educational Review, 78(1), 40-59.

Shanahan, T., \& Shanahan, C. (2012). What is disciplinary literacy and why does it 
matter? Topics in Language Disorders, 32(1), 7-18.

Shanahan, C., Shanahan, T., \& Misischia, C. (2011). Analysis of expert readers in three disciplines: History, mathematics, and chemistry. Journal of Literacy Research, 43(4), 393-429.

Spires, H. A., Kerkhoff, S. N., \& Paul, C. M. (2020). Read, write, inquire: Disciplinary literacy in grades 6-12. Teachers College Press.

Thein, A. H., Guise, M., \& Sloan, D. L. (2015). Examining emotional rules in the English classroom: A critical discourse analysis of one student's literary responses in two academic contexts. Research in the Teaching of English, 49(3), 200-223.

Times Higher Education. (2019). World university rankings 2019. https://www.timeshighereducation.com/world-university-rankings/2019/worldranking\#!/page/0/length/25/sort_by/rank/sort_order/asc/cols/stats

Warren, J. E. (2011). "Generic" and "specific" expertise in English: An expert/expert study in poetry interpretation and academic argument. Cognition and Instruction, 29(4), 349-374.

Wineburg, S. S. (1991). Historical problem solving: A study of the cognitive processes used in the evaluation of documents and pictorial evidence. Journal of Educational Psychology, 83(1), 73-87.

Wineburg, S. S. (2005, May). What does NCATE have to say to future history teacher? Not much. Phi Delta Kappan, 86(9), 658-665. https://doi.org/10.1177/003172170508600909

$\mathrm{Xu}, \mathrm{D}$. (2016). Assistance or obstacle? The impact of different levels of English developmental education on underprepared students in community colleges. Educational Researcher, 45(9), 496-507.

\section{Literature Cited}

Akana, K. (2014). Da 23 ${ }^{\text {rd }}$ Psalm. Tinfish 14 (p. 70). Tinfish Press.

Carson, A. (2013). Red Doc >. Vintage Books.

Conrad, J. (1990). Heart of Darkness. Dover Publications.

Heaney, S. (1995). The redress of poetry. Farrar, Straus, and Giroux.

Homer. (1990). The Illiad (R. Fagles, Trans.). Penguin.

Homer. (1996). The Odyssey (R. Fagles, Trans.). Penguin.

Kihleng, E. (2008). Lokaiahn Wai. In My Urohs (pp.38-39). Kahuaomanoa Press.

Kushner, T. (2013). Angels in America: A gay fantasia on national themes. Theater Communications Group.

LeGuin, U. K. (1968). A wizard of Earthsea. Houghton Mifflin.

LeGuin, U. K. (1970). The tombs of Atuan. Aladdin.

LeGuin, U. K. (1972). The farthest shore. Simon Pulse.

Rakoff, D. (2013). Love, dishonor, marry, die, cherish, perish: A novel. Doubleday.

Shakespeare, W. (2012). Hamlet. Simon and Schuster.

Shakespeare, W. (2018). Richard III. Simon and Schuster.

Shelley, M. (1994). Frankenstein. Dover Publications.

Stevenson, R. L. (2002). The strange case of Dr. Jekyll and Mr. Hyde. In B. Menikoff

(Ed.), The complete stories of Robert Louis Stevenson: Strange case of Dr. Jekyll and Mr. Hyde and nineteen other tales (pp.251-324). The Modern Library. 
Stevenson, R. L. (n.d.). The cart-horses and the saddle-horse. https://ebooks.adelaide.edu.au/s/stevenson/robert_louis/s848f/chapter14.html

\section{Author Biography}

Eric D. Rackley is an associate professor of education in the Faculty of Teacher Education at Brigham Young University-Hawaii. He is a former secondary English teacher. His research focuses on religious and disciplinary literacies of experts and novices. 